\title{
SOBRE ETHOS, JORNALISMO E CONSTITUIÇÃO: O GÊNERO OMBUDSMAN
}

\author{
ABOUT ETHOS, JOURNALISM AND CONSTITUTION: THE OMBUDSMAN GENRE
}

\author{
Atílio Butturi Junior \\ Doutorando do Programa de Pós-graduação em Linguística - UFSC \\ Morgana Carina Lenzi \\ Mestranda do Programa de Pós-graduação em Linguística - UFSC
}

\begin{abstract}
Resumo
O presente artigo pretende, a partir das discussões acerca da noção de gêneros do discurso na Análise do Discurso de linha Francesa, apontar algumas estratégias enunciativas da coluna ombudsman, no intuito de pensá-la como gênero no interior da esfera do jornalismo. Para tanto, recorre aos conceitos de cenografia, ethos e discurso constituinte, na medida em que esses conceitos possibilitam aduzir do discurso do ombudsman uma tendência de legitimação do campo jornalístico e de crítica geral aos mais variados campos do saber, o que o configuraria como espaço incipiente de assunção de um discurso como condição privilegiada de acesso ao verdadeiro e incluiria o gênero na estratégia de constituição de um efeito de discurso constituinte.
\end{abstract}

Palavras-chave: Ombudsman. Gêneros discursivos. Ethos. Cenografia. Discurso constituinte.

\begin{abstract}
The present article aims, from the discussions concerning the notion of speech genres in French Discourse Analysis, to point out some enunciative strategies of the column ombudsman, intending to think of it as a genre within the journalistic sphere. In order to do so, it uses the concepts of scenography, ethos and constituent discourse, as long as these concepts make it possible to adduce from the speech of the ombudsman a tendency of legitimation of the journalistic field and of general criticism to the most varied fields of the knowledge, what would configure it as an incipient space of assumption of a discourse as a privileged condition of access to the true and it would include the genre in the strategy of constitution of an effect of constituent discourse.
\end{abstract}

Key-words: Ombudsman. Speech genres. Ethos. Scenography. Constituent discourse.

\section{INTRODUÇÃO}

Quando se pensa no jornalismo como o quarto poder, como uma espécie de maquinaria geral e universalizante de crítica a toda sorte de acontecimentos e como locus de instituição de um poder metaexplicativo, é interessante relacionar essa configuração que parece se delinear aos seus enunciados e discursos e à empresa do próprio campo de, ao se autonomizar, garantir uma diferenciação ética e uma legitimidade diante de outros campos que tinham essa prerrogativa, como a ciência, a religiosidade e a arte. 
Este trabalho, então, recorre a uma das formas do jornalismo que mais aponta à empresa de legitimação e veridicção do campo: a coluna do ombudsman. Para tanto, parte do conceito de gênero desenvolvido na Análise de discurso de Maingueneau (1989, 2002, 2008), a fim de inquirir sobre as modalidades de apropriação de um discurso sobre o verdadeiro, relacionando, para tanto, gêneros discursivos, ethos jornalístico e, finalmente, a noção de discursos constituintes, que será aproximada das quatro modalidades de dizer verdadeiro descritas por Michel Foucault no curso Le courage de la verité (FOUCAULT, 2009).

O corpus de análise será composto das colunas do ombudsman on line de dois jornais, Folha de S. Paulo (jornal de São Paulo) e O Povo (jornal de Fortaleza), publicadas no período de 13 de dezembro de 2008 a 25 de janeiro de 2009. O tratamento desses enunciados não se pretenderá exaustivo como estruturação de um gênero - "o" ombudsman -, mas pretenderá esclarecer que mecanismos são solicitados na constituição de um discurso legítimo do jornalismo, o que defendemos como hipótese de trabalho para a coluna do ombudsman.

\section{DISCURSO E GÊNEROS DISCURSIVOS}

A discussão da Análise do discurso (AD) entabulada por Dominique Maingueneau está no escopo das mudanças ocorridas neste campo a partir do declínio do paradigma marxista-psicanalítico-estrutural precedente. Assim, ao se utilizar de teorias pragmáticas, textuais e, sobretudo, ampliar os corpora de análise, a tentativa desse programa de discurso é um aumento de complexidade rumo a uma excelência heurística.

No entanto, de acordo com Maingueneau (1989), é preciso não se perder de vista que, apoiando-se em métodos lingüísticos, a $\mathrm{AD}$ está calcada sobre um ponto de vista acerca de textos específicos, produzidos

- no quadro de instituições que restringem fortemente a enunciação;

- nos quais se cristalizam conflitos históricos, sociais, etc.;

- que delimitam um espaço próprio no exterior de um interdiscurso limitado. (MAINGUENEAU, 1991, p.13-14).

Se, por um lado, o fundamental é pensar as regularidades - sobretudo partindo do conceito foucauldiano de formação discursiva -, Maingueneau (2008) sugere que se pense em duas modalidades distintas, quais sejam: as unidades tópicas e as não-tópicas do discurso. Ao detalhar cada uma das categorias, o autor considera que as unidades tópicas estão divididas em duas ordens: territoriais, aproximadas de setores e instituições específicos, numa relação constitutiva entre gêneros de discurso e aparelhos; transversas, que "atravessam" as territoriais de três formas, quais sejam, linguística, funcional e comunicacional.

As categorias não-tópicas, de outro lado, são construtos teóricos do pesquisador, como a de formação discursiva: recortam o interdiscurso sem a necessidade de fronteiras preestabelecidas, pois não trabalham com noções como instituição, aparelho e afins. Heterogêneas, são o que Maingueneau estabiliza na forma da formação discursiva 
foucauldiana, "extraídas do interdiscurso, sem procurar construir espaços de coerência, constituir totalidades" (MAINGUENEAU, 2008, p.23).

Pelo viés dessa topicalização territorial sempre-já atravessada pelo atópico das formações discursivas é que se constrói um saber acerca dos gêneros discursivos. Maingueneau (2003) aponta que, não obstante a ausência de uma problemática relativa aos gêneros do discurso na $\mathrm{AD}$, certas regularidades não podem ser ignoradas pelo analista, pois correspondem a necessidades recorrentes na vida cotidiana. $O$ francês aponta que já existem critérios de natureza diversa para se pensar uma teoria de gêneros, quais sejam: funcionais, ligados aos subcódicos de Jakobson; de situação comunicativa, cuja perspectiva é pensar gênero pelo viés do dispositivo comunicacional sóciohistórico; linguístico-discursivos, calcados na distinção de Benveniste entre discurso e história e seus sistema dêitico.

Maingueneau (2003) então sugere a possibilidade de, via teoria do discurso, repensar a categoria gênero. Se, pois, os gêneros são categorias sociais constituídas pela linguagem, sua configuração não deve ser pensada pelo enfoque formal, mas da perspectiva do êxito alcançado pela atividade, tal como um ato de linguagem. Deste modo, as condições de felicidade de um gênero respondem a cinco critérios: finalidade reconhecida; estatuto legítimo dos parceiros; momento e lugar legítimos; suporte material; e organização textual.

Como instanciação linguageira, os gêneros do discurso devem, pois, ser aduzidos, pragmaticamente, na ordem de três domínios metaforizados: "jurídico (contrato), lúdico (jogo) e teatral (papel)” (MAINGUENEAU, 2003, p. 69). Dissequemos essa definição.

Quando parte de um entendimento dos gêneros como contrato, a análise do discurso pretende fazer ver seu caráter radicalmente normatizador - os gêneros têm normas e são criadores de comportamentos, porque performáticos - e cooperativo.

Segundo Maingueneau (2003, p.69), "Todo gênero do discurso exige daqueles que dele participam a aceitação de um certo número de regras mutuamente conhecidas e as sanções previstas para quem as transgredir. Evidentemente, esse 'contrato' não necessita ser objeto de um acordo explícito.”. Na mesma esteira, o gênero é pensado como jogo que requer a obediência ao regramento, ainda que passível de variação e transformação.

Finalmente, os gêneros demandam um critério representacional, esvaziado enquanto subjetividade (pessoal ou assujeitada), mas investido da capacidade de ação dentro do contrato e sob a égide do jogo, como papel: "Falar de papel é insistir no fato de que cada gênero de discurso implica parceiros sob a ótica de uma condição determinada e não de todas as suas determinações possíveis” (MAINGUENEAU, 2003, p.70).

Maingueneau (2003) recorre ainda a uma subsunção: o gênero estaria englobado pelo tipo de discurso, já que este último tem caráter englobante e universalizante. Dito de outro modo: os tipos de discurso dizem respeito a setores mais amplos da atividade social e existem como "discurso midiático", "político" etc., enquanto os gêneros aparecem como enunciados regulares no interior das tipologias. 
Dessa categorização, surgiria uma outra, devidamente pautada na metaforização teatral: o quadro cênico a que se relacionam os discursos. De um lado, há uma cena englobante, da ordem dos tipos de discurso. Por outro, uma cena genérica [de gêneros], pela qual se é capaz de inferir papéis, jogos e contratos mais circunscritos, ou seja, definir gêneros na ordem dos tipos.

Todavia, Maingueneau (2003) traz à tona a seguinte questão: ao nos depararmos com discursos, não temos acesso direto a esse quadro cênico, mas apenas à cenografia, espécie de reduplicação imanente da enunciação, de materialização das cenas. A cenografia legitima (trazendo o efeito de verdadeiro, no caso da imprensa) e constitui o enunciado em sua materialidade, no momento em que esse enunciado adapta a cena genérica e a englobante na empresa de persuasão e engajamento do coenunciador. Relacionadas aos gêneros, as cenografias podem ser mais ou menos variadas, de acordo com a finalidade dos discursos.

Como se pode notar, o empreendimento genérico, em Maingueneau, responde sempre à necessidade social e se empenha em atentar para os modos pelos quais as regularidades do discurso demandam a atuação do par enunciativo, para fins de persuasão e aderência. Pensar gêneros, pois, diz respeito a averiguar a identidade desses actantes, problematizada via ethos.

\section{ETHOS E GÊNEROS DISCURSIVOS}

Em termos gerais, o ethos é definido por Maingueneau $(2003,2008)$ como uma maneira de dizer que estabelece modos de ser, dentro do discurso, do enunciador e do coenunciador, garantindo a identificação entre esses e a felicidade do gênero.

A noção é tomada da filosofia grega - a Retórica aristotélica -, na qual correspondia à criação de uma imagem legítima do orador, baseada no jogo instaurado com a enunciação (o critério, portanto, não é exterior à fala). Maingueneau (2008, p. 64) esclarece que, no seu quadro discursivo, utilizou-se do conceito para empreender análises relativas aos discursos instituídos, aqueles em que os "parceiros ocupam papéis preestabelecidos e seguem rotinas mais ou menos precisas no desenvolvimento da organização textual”.

Utilizar o conceito de ethos, pois, corresponde a perscrutar o modo de adesão do sujeito ao seu discurso na modalidade do posicionamento: é mister fazer convergir um ethos a um papel na cena genérica, no intuito de persuadir outrem acerca da verdade do que é enunciado. Ademais, o ethos transcende o modelo do estatuto, pois recorre a uma subjetividade, que Maingueneau assume como uma vocalidade da ordem do corpo (discursivo, é bom que se diga), e a um caráter da ordem do psicológico, a uma marca que corrobora a situação fiduciária de todo dizer:

O "caráter" corresponde a um feixe de traços psicológicos. Quanto à "corporalidade", ela é associada a uma compleição física e uma forma de se vestir. Além disso, o ethos implica uma forma de mover-se no espaço social, uma disciplina tácita do corpo, apreendida por meio de um comportamento. (MAINGUENEAU, 2008, p. 65). 
Disciplina discursiva dos corpos, o efeito do ethos é o de um cuidado de si, cuja finalidade é criar uma identidade do enunciador para o coenunciador, garantindo a adesão ao discurso e o sucesso do gênero e da cenografia. "Incorporação", nos termos de Maingueneau (2002), seria justamente a ação do ethos quando relacionada às crenças do coenunciador em relação à verdade do enunciador, o fiador do dizer.

Trata-se de relações de identificação de ordem subjetivante, mas calcadas em construções estereotipadas pelos gêneros e pelas tipologias discursivas:

Tomado pela leitura em um ethos envolvente e invisível, participa-se do mundo configurado pela enunciação, acede-se a uma identidade de certa forma encarnada. $\mathrm{O}$ poder de persuasão de um discurso decorre em parte do fato de que ele leva o destinatário a identificar-se com o movimento de um corpo, por mais esquemático que seja, investido de valores historicamente especificados. (MAINGUENEAU, 2008, p.72).

Se as relações que permeiam os gêneros são da ordem dos sujeitos e das regularidades sócio-históricas, passemos a discorrer acerca de um grupo de discurso que dá tratamento específico a estas questões: os discursos constituintes.

\title{
3.1 Os discursos constituintes
}

Maingueneau (2000) revela que, diante da miríade de corpus com que vem se debatendo, uma categoria específica merece destaque, a saber, a dos discursos constituintes. Tais discursos seriam aqueles vinculados ao arquéion de todos os grupos sociais:

\begin{abstract}
Esse termo grego, étimo do latino archivum, apresenta uma polissemia interessante para nossa perspectiva: ligado a arché, "fonte", "princípio", e a partir daí "mandamento", "poder", o archéion é a sede da autoridade, um palácio, por exemplo, um corpo de magistrados, mas também os "arquivos públicos". O archéion associa assim intimamente $\mathrm{o}$ trabalho de fundação no e pelo discurso, à determinação de um lugar associado a um corpo de enunciadores consagrados, e à elaboração de uma memória. (MAINGUENEAU, 2000, p.7).
\end{abstract}

Os discursos constituintes são explicados "banalmente" por Maingueneau (2000) como aqueles que são exigidos pelos sujeitos em todas as ocasiões em que se pretenda conhecer a verdade acerca dos objetos do mundo. Nesse caso, os exemplos prototípicos seriam o discurso religioso, o científico e o filosófico. Como categoria, sua característica de fundante ficaria patente por uma assimetria diante dos demais discursos, baseada não apenas no poder exercido na imanência sobre os demais discursos, mas na capacidade de estabelecer o vínculo com o transcendente.

Se pensarmos na distinção já mencionada entre gênero do discurso e tipo de discursos, os discursos constituintes seriam um tipo, justamente por subsumirem os gêneros. Metaexplicativos dos gêneros, portanto, tais discursos estariam num ponto-limite, apontando o paradoxo de seu regime de dizer: autoconstituídos, ao se voltarem amiúde para a arqueologia de sua constituição; heteroconstituídos, por se legitimarem como 
instância metaexplicativa na constituição dos demais discursos (MAINGUENEAU, 2000).

Maingueneau (2008) faz notar, entretanto, que o estatuto desses discursos não é facilmente determinável e não pode ser aduzido das tipologias disponíveis. Todavia, esses discursos guardariam em comum três características tipológicas: teriam como função dispor de autoridade, sua situação de comunicação seria específica e ligada a certos gêneros sociais, além de trazer no bojo um quadro de invariação enunciativa (MAINGUENEAU, 2008).

Ademais, nesta esteira de definição categórica, o francês aponta para outra característica determinante dos discursos constituintes, a paratopia. O discurso constituinte, justamente por seu caráter essencialista, não pode recorrer à marca de uma subjetividade, à atividade de um autor. Logo, no movimento em que aciona a autoria, deve se desfazer desta em nome de algo que está além do subjetivo, uma espécie de desterritorialização cuja função princeps é mesmo a de garantir a diferença entre um discurso constituinte e os demais discursos. Assim, novamente esse discurso deve ser pensado como paradoxal, visto que:

Sem "localização", não há instituições que permitam legitimar e gerir a produção e o consumo de obras; mas sem "des-localização" não há verdadeira obra, porque é uma força que excede toda a sociedade que confere legitimidade aos que falam desde o interior dos discursos constituintes. (MAINGUENEAU, 2008, p. 46).

Performáticos - porque fundam sua própria série enunciativa - e circulares - porque recorrem aos seu próprios enunciados a fim de comentar e legitimar seu campo -, os discursos constituintes operam estrategicamente na empresa de manutenção da ordem do que se enuncia. Daí, são uma tipologia da qual emanam diversos gêneros, num processo em que textos fundadores devem ser amplamente retomados e comentados, segundo as regularidades que de antemão prescrevem (MAINGUENEAU, 2008).

Entendendo, pois, o viés estratégico dos discursos constituintes e sem a pretensão de gramaticalizar uma categoria, passemos ao caso do gênero ombudsman, cuja cenografia vai sugerir uma estratégia de assunção do jornalismo como fonte legitimada dos discursos ou, nos moldes estabelecidos por Maingueneau (2000, 2008), encetar uma problemática típica de discursos constituintes.

\section{ETHOS, PARRÊSIA E CONSTITUIÇÃO: A COLUNA DO OMBUDSMAN}

Então vejamos: uma cenografia distinta pode ser delineada ao nos depararmos com a coluna do ombudsman. Por conseguinte, como gênero, sua regularidade deverá ser buscada na recorrente manutenção de duas vertentes de crítica: a do jornal e sua relação com a esfera jornalística, a cena englobante, que garante a vinculação ao tipo; a do jornal em relação ao noticiário semanal, fazendo apontamentos críticos, dando sugestões e respondendo aos leitores.

Dessa perspectiva, é no próprio corpus de análise que se podem encontrar as principais atribuições desse cargo, baseadas num ethos de autoridade e de polêmica. De acordo 
com os sites dos jornais Folha de S. Paulo e O Povo, na seção "O que é o cargo" e "O que é o ombudsman", respectivamente, o ombudsman, na esfera jornalística, "é um profissional dedicado a receber, investigar e encaminhar as queixas dos leitores; realizar a crítica interna do jornal e, uma vez por semana, aos domingos, produzir uma coluna de comentários críticos sobre os meios de comunicação"1 e, reforçando a conceituação, "tem a obrigação de produzir uma crítica interna diária, escrever uma coluna semanal, publicada na edição de domingo, e atender os leitores por telefone, fax, e-mail, carta e pessoalmente",2.

O que se aduz desses recortes são os papéis desempenhados pelo ombudsman: ser um crítico e um elo entre jornal e leitor. Daí o caráter paradoxal de sua função, a um só tempo legitimada pelo jornal e artífice de sua crítica mais ferrenha. Ethos cuja constituição é sempre cindida: sendo um crítico, repousa sobre ele a pressuposição de ser um sujeito com notório conhecimento e experiência, uma vez que irá avaliar, julgar, recomendar e tecer comentários e opiniões; no que diz respeito à função de intermediário entre jornal e leitor, surge um interessante questionamento: como se dá a escolha do ombudsman? Geralmente pela indicação da presidência ou diretoria do grupo de comunicação a que está vinculado o jornal. Isso implica, evidentemente, um efeito de identidade.

A fim de esboçar o funcionamento discursivo do gênero ombudsman, recorremos a três tópicos: "Sobre autotelia", no qual discutimos a coluna como vértice entre o jornal e o campo jornalístico; "Sobre autoridade", no qual elaboramos uma problematização do ethos e da cenografia; e "Sobre o verdadeiro", no qual vinculamos o ombudsman à modalidade do discurso da sabedoria, trazendo em seu bojo, a partir daí, efeitos de discurso constituinte.

\subsection{Sobre autotelia}

Em As regras da arte, Bourdieu (1996) apresenta a noção de campo como um discurso que, no interior da circulação discursiva, tem autonomia relativa e regras próprias sem, contudo, deixar de manter relações com a exterioridade. Em Maingueneau (2000, 2008), a noção de campo pode ser aproximada do conceito de tipo de discurso: uma série enunciativa que organiza discursos na forma de gêneros. Aqui, então, é mister relacionar tipo jornalístico com gênero ombudsman, justamente para inquirir acerca da constitutividade entre uma cena englobante e uma cena genérica.

Ao nos voltarmos para as colunas do ombudsman da Folha, no recorte temporal estabelecido de antemão, o que se pode notar, segundo parâmetros "quantitativos", é a insistência em se discutir o jornalismo como campo - ou como tipo - para somente então tratar dos assuntos pontuais, quais sejam, aqueles definidos para o cargo: fazer a ponte com os leitores e dirimir dúvidas, aceitando e debatendo críticas.

Destarte, das sete colunas analisadas, cinco se ocupam de discutir o jornalismo e suas implicações éticas gerais, para somente então passar aos questionamentos da Folha.

\footnotetext{
${ }^{1}$ Disponível em: < http://www1.folha.uol.com.br/folha/ombudsman/cargo.shtml >. Acesso em: 23/2/2010.

${ }^{2}$ Disponível em: <http://opovo.uol.com.br/ombudsman/ombudsman-o-que-e-ombudsman.html $>$. Acesso em: 23/2/2010.
} 
Ademais, o próprio título da coluna recorre à discursividade englobante, numa espécie de efeito de pertença: o ombdusman da Folha se institui na medida em que seu pertencimento ao jornalismo o torna legítimo; e, no mesmo movimento, promove e corrobora o jornalismo como discurso legítimo. A relação será, pois, de autotelia: discutir o noticiado no jornal tem o efeito especular de se remeter ao jornalismo como discurso primeiro. Leiamos:

O JORNALISMO é uma atividade que sempre viveu de contar ao público os fatos do passado recente. O grande dilema de suas versões impressas é como permanecer necessário se nada mais é novidade quando elas chegam ao leitor. (LINS E SILVA, Folha de S. Paulo, 14.12.2008) $)^{3}$.

O trecho acima é o início do texto no qual Lins e Silva ${ }^{4}$ se empenha em observar o papel da imprensa na cobertura de situações sociais tensas. No caso específico, tratava-se das enchentes no Estado de Santa Catarina, mas o que é importante notar é a amplitude da temática, já que não se trata apenas de elaborar críticas à cobertura, mas de criar um parâmetro, uma axiologia segundo valores da tipologia jornalística. O próprio título do texto corrobora a hipótese: "Muitas outras águas ainda vão rolar". Não se trata de um esforço da ordem do acontecimento - as chuvas e a cobertura -, mas da ordem da estrutura do campo jornalístico.

Na semana seguinte, algo similar ocorre: o título do texto publicado é "Jornalismo e direitos humanos" e o ombudsman faz reflexões acerca dos parâmetros de conduta a que se submeteu o jornalismo com a criação, há sessenta anos, da Declaração Universal dos Direitos Humanos. Quando se volta para o impacto do jornalismo no Brasil, o discurso do ombudsman pretende relacionar a Folha à cena englobante:

A pesquisa encomendada pela Secretaria dos Direitos Humanos da Presidência da República comprova isso, ao constatar que apenas $20 \%$ da população a aponta como um dos três fatores mais importantes para garantir os direitos (bem abaixo da família, do indivíduo, do governo e da Justiça, entre outros).

Para ser agente da implementação desses direitos, não basta ao jornal denunciar o seu desrespeito pontual. Ele precisa acompanhar metodicamente e de maneira competente a formulação e aplicação das políticas públicas que os envolvem. (LINS e SILVA, Folha de $S$. Paulo, 21.12.2008) $)^{5}$.

O escopo da coluna do ombudsman não se restringe ao jornal no qual ocupa função, mas aponta para as relações entre o que seria o "Jornalismo", enquanto campo discursivo autonomizado, e sua "manifestação" derradeira, o ombudsman. Por este viés, a estratégia é sempre discutir a Folha, discutindo o jornalismo. Relação constitutiva, pois exige que, para que um permaneça legítimo, o outro mantenha sua credibilidade e faça jus ao seu ethos de crítico "autônomo".

\footnotetext{
${ }^{3}$ Disponível em: <http://www1.folha.uol.com.br/fsp/ombudsma/om1412200801.htm>. Acesso em $10 / 2 / 2009$.

${ }^{4}$ Carlos Eduardo Lins da Silva, ombudsman do jornal A Folha de S. Paulo desde 22 de abril de 2008.

${ }^{5}$ Disponível em: <http://www1.folha.uol.com.br/fsp/ombudsma/om2112200801.htm>. Acesso em 10/2/2009.
} 


\title{
4.2 Sobre autoridade
}

Se assumirmos como estratégia discursiva da coluna do ombudsman o caráter de constitutividade marcada com o campo jornalístico, na medida em que se recorre amiúde à cena englobante para garantir a posição de crítica, é de um ethos de autoridade que se valerá o ombudsman. Dito de outro modo, o ethos do ombudsman traz no bojo a perspectiva autotélica - é um crítico às voltas com a discussão teórica de seu campo de atuação - e a da metacrítica, pois sua modalidade de enunciação é a que guarda os privilégios de quem circula pelo verdadeiro, pelo reto, pelo arrazoado.

Efeito marcado nos enunciados, esse ethos de autoridade típico do gênero em questão surge numa seção fixa do ombudsman da Folha, a "Para ler/Para ver", na qual Costa e Silva sugere leituras e filmes afins ao que a coluna discutiu. Ethos pedagógico, portanto, que emana de uma enunciação que se pretende disciplinadora do jornal, do jornalismo e do "refinamento" do próprio leitor. Além disso, ethos de identificação com o leitor da Folha, pois os textos indicados (sobretudo filmes e livros recém lançados) pertencem ao circuito comunicativo dos leitores da Folha, supostamente para quem o ombudsman fora criado. Leia-se:

\begin{abstract}
PARA LER
"A Criança e a Mídia", de Cecília von Feilitzen e Ulla Carlsson (org.), tradução de Dinah de Abreu Azevedo e Maria Elizabeth Santo Matar, Cortez, 2002 (a partir de R\$36,26) - Textos mostram como se dá a relação entre mídia e crianças em 26 países em abordagens inteligentes e interessantes

"Ler Sem Engasgar", de Mônica Pinto Rodrigues da Costa (dissertação de mestrado da PUC-SP), 1982 - Um estudo de recepção do suplemento Folhinha, deste jornal, entre alunos de dois colégios de São Paulo
\end{abstract}

\section{PARA VER}

"Em Busca da Terra do Nunca", de Marc Foster, com Johnny Depp e Kate Winslet (a partir de R\$ 19,90) - Bela biografia ficcional do autor de "Peter Pan", J. M. Barrie, mostra a importância da leitura e da escrita para crianças

(LINS E SILVA, Folha de S. Paulo, 18.01.2009) ${ }^{6}$.

Importante: a coluna do ombudsman que fez as indicações acima, "Como atrair os jovens para o jornal”, do dia 18 de janeiro de 2009, é um exemplo paradigmático do gênero: por um lado, tem início discutindo a suposta falência da leitura e conjecturando acerca do valor do jornalismo para a transformação social, o que poderíamos aduzir como o efeito de autotelia da seção precedente. Por outro lado, na busca da ordem e da unidade - mecanismos caros às disciplinas discursivas -, são indicados textos que corroboram a hipótese do jornal como espaço salutar de apropriação da língua escrita.

\footnotetext{
${ }^{6}$ Disponível em: < http://www1.folha.uol.com.br/fsp/ombudsma/om1801200903.htm >. Acesso em $10 / 2 / 2009$
} 
Este ethos de autoridade, que permite uma pedagogização dos discursos e vislumbra o discurso do verdadeiro, ganha destaque quando se trata de entabular discussões com os demais jornalistas e seus "erros" de cobertura - no caso do ombudsman, "erros" gramaticais" também são mote de acaloradas digressões.

Novamente, corroboremos a hipótese via apresentação de recortes dos dados. Para tanto, apresentamos parte da última coluna de 2008 do ombudsman da Folha, que sugere 12 resoluções para o novo ano para que o jornal possa melhorar seu desempenho, das quais apresentamos três:

\section{$[\ldots]$}

\section{RESPOSTAS AO LEITOR}

Que todos os jornalistas, colunistas, articulistas respondam com presteza e civilidade às manifestações recebidas dos leitores, que são a justificativa para o espaço que têm no jornal e o pagamento que recebem dele. [...]

$[\ldots]$

\section{PREVENÇÃO}

Que se exerça mais o jornalismo preventivo, com o acompanhamento sistemático de políticas públicas, debate aprofundado e antecipado de matérias em tramitação nos Legislativos, cobrança metódica das autoridades públicas sobre seus planos, medidas e ações no sentido de amenizar efeitos de problemas previsíveis, como inundações e dificuldades de tráfego urbano, interurbano ou aéreo. [...].

\section{$[\ldots]$}

\section{PORTUGUÊS}

Que, apesar da reforma ortográfica a ser implantada em 2009, a Redação seja capaz de fazer diminuir a quantidade de erros gramaticais que ainda infestam o jornal e irritam o leitor.

(LINS E SILVA, Folha de S. Paulo, 28.12.2008) ${ }^{7}$.

Evidentemente que aqui a idéia de "conselheiro" pode ser substituída por um relatório das principais ou recorrentes críticas apontadas na coluna ao longo do ano que se finda, o que seria uma espécie de balanço das atividades. No entanto, a habilitação dada pelo jornal ao ombudsman para enunciar dessa forma traz o efeito de autoridade do editorchefe ou presidente do conselho do jornal, mesmo que o modo verbal seja o subjuntivo e não o imperativo, tendo em vista o acento de normatização que subjaz às resoluções listadas, tais como: Que todos os jornalistas, colunistas, articulistas respondam com presteza e civilidade às manifestações recebidas dos leitores; Que se exerça mais o jornalismo preventivo; [...] que seja mais criativo, inovador, ousado para surpreender o leitor quando este o abrir diariamente.

O que se pode verificar é que a marca de autoridade que credencia, portanto, o ombudsman a dar a solução para determinados problemas, reside numa espécie de crença de que ele seja um detentor da verdade, um metacrítico, uma vez que, além de

7 Disponível em: < http://www1.folha.uol.com.br/fsp/ombudsma/om2812200801.htm >. Acesso em $10 / 2 / 2009$. 
aconselhar seus pares e demais profissionais ligados à esfera jornalística, também é autorizado a emitir julgamentos e direcionar caminhos para assuntos de outras esferas, tais como política, religiosa e jurídica.

Sob essa ótica, tomemos a coluna do ombudsman de $O$ Povo do dia 12 de janeiro de 2009, a primeira da nova ombudsman, que acabara de assumir a coluna. Ao discorrer sobre sua função, Rita Célia Faheina ${ }^{8}$ expõe:

[...] O ombudsman também faz, diariamente, a análise das matérias publicadas na edição do jornal e envia para a primeira reunião da pauta do dia, pela manhã. Cabe ao profissional que exerce a função as sugestões e cobranças sobre a correção de erros, falhas, imprecisões, equívocos e direitos de resposta. É o que está no Regimento do Cargo de Ombudsman do O POVO. (FAHEINA, O Povo, 12.01.2009) ${ }^{9}$.

Para garantir o ethos de autoridade, ancorado no campo que o precede, na forma de saber organizado e legítimo, o profissional que ocupar esse cargo precisa ter conhecimento profundo, teórico e prático, do âmbito jornalístico, bem como ser um conhecedor de todas as questões pontuais que merecem destaque e surgem como debate no cenário midiático. Por ter a incumbência de fazer a análise de todas as matérias que serão publicadas no jornal, outro requisito parece ser indispensável para exercer a função de ombudsman: deve o jornalista escolhido ter entendimento sobre a cenografia dos diferentes gêneros pertinentes à cena englobante, o discurso jornalístico. Daí o esforço de reivindicar um histórico validado dentro do discurso, como no caso da apresentação da nova ombudsman de $O$ Povo:

[...] A nova ombudsman, Rita Célia Faheina, assume o cargo no próximo dia 7. É repórter do Núcleo de Cotidiano do O POVO (faz matérias para as páginas de Ceará) e está neste jornal desde 1988. É detentora de importantes prêmios de reportagem (nacionais, inclusive). Tem formação católica, mas é uma pessoa de espírito aberto a todas as crenças e respeita até os que não têm crenças como este ombudsman, além de ser notável figura humana. Sucesso, Ritinha. (VERLAINE ${ }^{10}$, O Povo 3.1.2009, grifos nossos) ${ }^{11}$.

O ocupante do cargo de ombudsman, tendo em vista sua carreira/perfil, que o destaca para tanto, além de proferir discursos com forte acento de autoridade, por reflexo, também emana discursos cujo principal acento é a demonstração de sua sabedoria/erudição/conhecimento. Nesses casos, não tem como foco principal demonstrar "uma saída", a solução, mas sim expressar seu conhecimento, que o permite ter gabarito para discutir sobre o tema em questão.

\footnotetext{
${ }^{8}$ Rita Célia Faheina, ombudsman do jornal O Povo entre janeiro de 2009 a janeiro de 2010.

${ }^{9}$ Disponível em: < http://opovo.uol.com.br/opovo/colunas/ombudsman/848902.html >. Acesso em 23/2/2010.

${ }^{10}$ Paulo Verlaine, ombudsman do jornal O Povo entre janeiro de 2008 a janeiro de 2009.

${ }^{11}$ Disponível em: < http://www.observatoriodaimprensa.com.br/artigos.asp?cod=519VOZ002 $>$ e

$<$ http://opovo.uol.com.br/ombudsman/847643.html >. Acesso em 23/2/2010.
} 
No que tange à capacidade irrestrita de circulação pelos outros gêneros - e cadernos do jornal, a coluna de 14 de dezembro de 2008 da Folha, ao debater a "falência" da Ilustrada - o caderno de cultura do jornal - é, novamente, exemplar:

[...] Minha impressão é a de que o caderno vem se tornando um guia de consumo e encara a cultura como simples mercadoria. Por isso, não suscita controvérsia, não anima polêmica, não ajuda a pensar. (LINS SILVA, Folha de S. Paulo, 14.12.2008 ${ }^{12}$ ).

O ombudsman, aqui, assume a enunciação e, dessa filtragem subjetiva, faz notar a "corrupção" da Ilustrada. Mais do que um mediador entre os leitores - que saldavam ou reclamavam do caderno - e os redatores do caderno, é a opinião metacrítica de Lins e Silva que se torna instrumento de modificação daquilo que, na Folha, não obedece ao campo de forma devida. Mais próxima do verdadeiro e mais eticamente relacionada à esfera jornalística, a opinião do ombudsman tergiversa acerca da arte, da política, da religião e de toda sorte de discursos. Vamos a outro exemplo, desta feita claramente revelador da instanciação de superioridade legada ao ombudsman:

O problema é que a frase não foi dita pelo ex-presidente Lyndon Johnson. É atribuída a outro ex-presidente norte-americano: Franklin Delano Roosevelt, em 1939: "Somoza may be a son of a bitch, but he's our son of a bitch." Referia-se a Anastasio (Tacho) Somoza, ditador nicaragüense, pai de Anastasio (Tachito) Somoza, que também foi ditador do país, deposto em 1979 pelos sandinistas e morto em um atentado no Paraguai, onde se encontrava exilado.

Solicitei a correção no "Erramos", mas até sexta-feira ela não havia sido providenciada. Está feito o registro. (VERLAINE, O Povo, 27.12.2008) $)^{13}$.

É fundamental que se note o efeito de objetividade: ainda que se utilize da embreagem em primeira pessoa, o recorte é finalizado por "registro", o que exige do leitor um engajamento verifuncional - há uma verdade última, cuja transparência se dá na língua e no discurso, estas ferramentas que demandam correções ininterruptas.

Tais posicionamentos críticos, porém, não encerram uma negatividade. Dito de outro modo, a estratégia do ombudsman suplanta a negação crítica e aponta para uma produção positiva de realidade, uma realidade em que o jornal aparece como arauto da acuidade ética e, por extensão, o jornalismo como esfera de poder quase inquestionável.

Nesse sentido, contudo, o ombudsman parece, em muitos casos, ser de fato um representante apenas do jornal, um conciliador ou porta-voz de defesa. Verificou-se que são recorrentes os elogios proferidos ao jornal ao qual está vinculado, bem como muitas das críticas apresentadas, são, por alguns recursos, suavizadas. Os trechos apresentados logo a seguir ilustram esse efeito.

\footnotetext{
${ }^{12}$ Disponível em: < http://www1.folha.uol.com.br/fsp/ombudsma/om1412200802.htm >. Acesso em $10 / 2 / 2009$.

${ }^{13}$ Disponível em: < http://www.observatoriodaimprensa.com.br/artigos.asp?cod=518VOZ004 $>$. Acesso em $23 / 2 / 2010$.
} 
No exemplo abaixo, a coluna intitulada "Cid e a crise" (O Povo, 13 dezembro 2006) traz a queixa de um leitor, segundo o qual, o jornal "compra o discurso do governador de que a crise econômica beneficiaria o Estado, sem ao menos ouvir empresários e economistas sobre até que ponto essa opinião é correta ou não". O ombudsman a responde com a voz de dois editores do jornal, cujo arremate assim se edifica:

Não temos dúvida que a decisão de publicar foi acertada. E mais acertada ainda foi a de aprofundar ao tema nos próximos dias. Do contrário, estaríamos revogando um princípio básico, o da factualidade". (VERLAINE, O Povo, 13.12.2008, grifos nossos) ${ }^{14}$.

É evidente que o ombusman não pode criticar o jornal/os jornalistas sem que sinta real necessidade disso. Não deve ele acatar todas as reclamações vindas dos leitores, mesmo porque para o mesmo fato haverá críticas e, simultaneamente, elogios. $\mathrm{O}$ que nos chama a atenção é, contudo, a seleção dos assuntos e o modo como são abordados.

Na mesma perspectiva de análise, transcrevemos os seguintes fragmentos:

É preciso reconhecer que, na passagem dos 40 anos do AI-5, o Diário do Nordeste bateu O POVO no que este jornal sempre foi melhor: o resgate dos fatos históricos". (VERLAINE, O Povo, 20.12.2008, grifos nossos) $)^{15}$.

Esse caso é de aparente crítica. Vem inclusive depois de uma seção em que Verlaine expõe a cobertura de $O$ Povo sobre os 40 anos da decretação do Ato Institucional Número 5, seção essa iniciada com a alegação de um leitor de que houve pouco destaque e aprofundamento por parte do jornal para um assunto tão importante. No entanto, o ombudsman, após a crítica citada do leitor, inicia uma espécie de relatório das matérias produzidas pelo periódico, utilizando expressões elogiantes, tais como: três bons artigos, outro bom artigo. Em seguida, contudo, a coluna apresenta outra seção: Concorrente aprofunda tema, fazendo uma comparação com o outro jornal concorrente, o Diário do Nordeste; mas, mesmo favorecendo o outro veículo de comunicação ("o Diário do Nordeste bateu $\boldsymbol{O}$ POVO"), deixa explícita a qualidade habitual e preferencial de seu jornal: "no que este jornal sempre foi melhor: o resgate dos fatos históricos".

A Folha igualmente evidencia, por meio da coluna do ombudsman, um discurso que vem conferir legitimidade ao jornal. Isso implica um efeito qualitativo e legitimante, visto que receber elogios de um profissional gabaritado - lembremos sempre que o locus de onde fala o ombudsman é uma coluna devidamente separada do restante da edição - traz uma carga axiológica positiva aos seus enunciados. Desta posição, atentemos ao recorte exemplar:

Desde que o jornal assegure que os vários lados em disputa tenham sua posição publicada de maneira mais ou menos equilibrada, ele estará cumprindo sua tarefa de fomentar o debate público. Creio que a Folha tem agido desse modo nestas duas semanas.

\footnotetext{
${ }^{14}$ Disponível em: $<$ http://www.observatoriodaimprensa.com.br/artigos.asp?cod=516VOZ004 >. Acesso em 23/2/2010.

${ }^{15}$ Disponível em: < http://www.observatoriodaimprensa.com.br/artigos.asp?cod=517VOZ004>. Acesso em $23 / 2 / 2010$.
} 
$[\ldots]$

No geral, no entanto, o jornal tem feito um bom trabalho neste caso. (LINS E SILVA, Folha de S. Paulo, 11.01.2009 ${ }^{16}$, grifos nossos).

Verifica-se que Lins e Silva, geralmente, apresenta primeiro a crítica, ou seja, faz garantir seu ethos de ouvidor, de um leitor solidário às queixas dos demais leitores e munido de ferramentas para expressar seu posicionamento e trazer soluções. No entanto, em seguida, não é raro constatar que se enuncia favoravelmente ao veículo de comunicação. Tal estratégia talvez esteja vinculada aos dois papéis que exerce: criticar e intermediar. Ao reproduzir uma queixa, ou por si próprio indicar um ponto fraco, faz os leitores acreditarem que está "do lado deles". Novamente, o ethos que se evidencia é o da identificação.

No entanto, com frequência, ao trazer um elogio para tentar suavizar a crítica apresentada, faz pensar que isso seja uma forma de mascarar a democracia, o diálogo, o espaço concedido aos leitores. Com isso, não se pode furtar à idéia de que a coluna do ombudsman queira fazer crer que seja uma garantia de diálogo, mas, na essência, o seu interesse maior não está voltado ao público leitor, mas, sim, ao próprio jornal. Então, é necessário pensar num ethos de autoridade, garantido pelo que chamaremos aqui de efeito de discurso constituinte.

\subsection{Sobre o verdadeiro}

Retomemos o que nos dizia Maingueneau (2000) acerca dos discursos constituintes. Hetero e autoconstituídos, seriam uma espécie de discurso cujo efeito seria o de anterioridade e o de prescrição dos regimes de dizer. Supostamente mais capazes de inteligir o mundo, esses discursos teriam autoridade sempre-já garantida, estando próximos do que se entende por tradição e, justamente por isso, seriam a fonte de onde os gêneros diversos poderiam surgir, tanto em seus aspectos formais, quanto na forma de comentários em relação ao discurso dominante.

Se, então, podemos perceber na coluna do ombudsman a empresa permanente de explicação metacrítica, baseada na referência de um campo de saber específico, o jornalístico, é importante que pensemos esse ethos e essa cenografia como elementos de efeito de discurso constituinte. Assim, ainda que, como relutava Maingueneau (2000), seja problemático inferir categorias fixas de DC, quando usamos efeito de discurso constituinte estabelecemos um debate com um processo ainda em curso, o da autonomização do jornalismo como discurso legítimo, lado a lado com aqueles constitutivos da ratio ocidental: a filosofia, a ciência, a religião, a arte.

Falar desse efeito é justamente discutir o estatuto de verdadeiro que a posição e o ethos do ombudsman exigem: há um privilégio e uma axiologia envolvidos nos enunciados da coluna, que não apenas dizem respeito ao sujeito e suas atribuições, mas, sobretudo, à modalidade enunciativa da cena englobante, ou seja, ao jornalismo como empresa de investigação e definição dos modos de veridicção.

\footnotetext{
${ }^{16}$ Disponível em: < http://www1.folha.uol.com.br/fsp/ombudsma/om1101200901.htm >. Acesso em $10 / 2 / 2009$.
} 
Desta perspectiva de discussão das modalidades do dizer verdadeiro e sua força estratégica, Foucault (2009) estabelece como objetivo discutir a forma historicizada de se questionar acerca do estatuto de verdade dos dizeres, tendo como foco a noção de parrêsia, o "franco falar". Isso posto, se há duas tradições que remontam à Antiguidade - conhecimento e espiritualidade -, o que pretende o arqueólogo é indagar o modo do verdadeiro que engaja o sujeito numa ética, num cuidado de si e num risco: a parrêsia. Nem um espelhamento direto entre sujeito e objeto, típico dos discursos racionalizantes (da ordem do gnôthi seauton), nem uma tentativa de persuasão sofística que prescinda da diferenciação entre verdadeiro e falso (da ordem da bajulação retórica), a relação entre sujeito e verdade, na parrêsia, guarda três especificidades:

Em somme, por qu'il y ait parrêsia, dans l'act de verité, il y ait: premièrement, manifestation d'um lien fondamental entre la vérité dite e la pensée de celui qui l'a dite; [deuxièment], mise em question du lien entre lês deux interlocuteurs (celui qui dit la vérité et celui auquel cette vérité est adressée). D'où ce nouveau trait de la parrêsia: elle implique une certaine forme de courage [...] (FOUCAULT, 2009, p. 13).

No entanto, parrêsia é apenas um das quatro modalidades utilizadas, segundo Foucault (2009), para descrever o discurso verdadeiro, quais sejam: a primeira, o dizerverdadeiro do profeta, caracterizado não pela palavra do sujeito, mas pelo papel deste como ferramenta, como mediador da voz dos deuses; a segunda, o dizer-verdadeiro do sábio, cuja estrutura é a do silêncio e da desobrigação ética, justamente porque se trata apenas de descrição neutralizante do mundo; a terceira, o dizer-verdadeiro do professor, encarregado da tekhnê, do saber-fazer com o mundo, implicado numa ausência de risco calcada no poder da tradição: ensinar é mesmo repetir e religar os discursos numa ordenação.

A quarta modalidade do dizer-verdadeiro, a do parresiasta, embora comprometida com cada uma das três outras de forma irremediável - os modos são funcionais e se entrecruzam constantemente -, é sempre lida sob o signo da transgressão da ordem ligada à ação da dobra subjetiva: o jogo da verdade e da alteridade que, ao inteligir o mundo, acaba por (re)construir as formas de subjetivação.

Tomemos Foucault (2009) à luz do conceito de discurso constituinte, elaborado por Maingueneau (2000). No gênero ombudsman, como observamos, a relação se dá sempre com a anterioridade, ou seja, é sempre remetida ao campo jornalístico instituído, com regras enunciativas claras. Além disso, o lugar do ombudsman é institucional e há um mecanismo de amplificação de seu poder e do poder do jornal conforme suas críticas sejam mais audaciosas e mais próximas da tentativa de estabelecimento de um lugarótimo para a crítica.

Nos termos foucauldianos, o discurso do ombudsman é o do acesso ao verdadeiro na modalidade da sabedoria: nem risco nem coragem, nem obrigação ética do sujeito, mas posição dentro de uma discursividade primeira, adequação do discurso à esfera (tipo discursivo) que o subsume. Desta posição, a crítica imediata ao jornal e a corroboração com as queixa dos leitores jamais são suficientes para destituir o poder do campo (tipo 
discursivo), mas são a forma por excelência de apresentá-lo como continuamente autocrítico e teleologicamente orientado.

Como gênero cuja modalidade de acesso ao verdadeiro é o da sabedoria, o mesmo ombudsman é credor do discurso que o circunscreve como tipologia, mantendo com este uma relação solidária por seu efeito de discurso constituinte funcional: o ombudsman seria, pois, o gênero em que um ethos de autoridade do colunista, baseado numa constante assunção de pertencimento à esfera jornalística, entabularia uma constitutividade entre um discurso constituinte em formação - e aqui pensemos num poderio crescente da dita "opinião pública" em sua vertente institucional - e o gênero, que depende deste incipiente discurso constituinte para se apresentar como legítimo, ético e verdadeiro.

\section{CONSIDERAÇÕES FINAIS}

Este artigo pretendeu problematizar a coluna do ombudsman como gênero dentro da tipologia do discurso jornalístico, fazendo notar o fato de que há relações específicas que apontam para um efeito de discurso constituinte presente no gênero.

Para tanto, percorreu alguns dos conceitos definidos por Maingueneau, como cena, cenografia e ethos, a fim de inquirir, nos dados, o funcionamento dessa estratégia, que percorre a tarefa do crítico interno.

Finalmente, consideramos como constitutivos o empreendimento de tomada de campo via assunção de um ponto de vista metacrítico e uma modalidade de dizer o verdadeiro baseada na sabedoria, que não implica risco, mas produção da verdade pautada na disciplina do discurso. Nesse caso, a hipótese que se defende é a de que temos no gênero ombudsman justamente um efeito de constituição tático no que tange ao poder e à legitimidade da esfera jornalística.

\section{REFERÊNCIAS}

BOURDIEU, P. As regras da arte: gênese e estrutura do campo literário. São Paulo: Companhia das Letras, 1996.

FOUCAULT, M. Le courage de la verité: le gouvernement de soi e des autres II, Cours au Collège de France, 1984. Paris: Gallimard, Seuil, 2009.

MAINGUENEAU, D. Cenas da enunciação. São Paulo: Parábola, 2008.

Análise de textos de comunicação. 2.ed. São Paulo: Cortez, 2002.

. Elementos de linguística para o texto literário. São Paulo: Martins Fontes, 2001.

Analisando discursos constituintes. Revista do GELNE, Fortaleza, v.2, n.2, p.167-178, 2000. 
Novas tendências em análise do discurso. Campinas, SP: Pontes: UNICAMP, 1989. 